\title{
Genetic polymorphisms of antioxidant enzymes CAT and SOD affect the outcome of clinical, biochemical, and anthropometric variables in people with obesity under a dietary intervention
}

César Hernández-Guerrero ${ }^{1 *}$ (D), Alicia Parra-Carriedo', Diana Ruiz-de-Santiago², Oscar Galicia-Castillo³, Mario Buenrostro-Jáuregui ${ }^{3}$ and Carmen Díaz-Gutiérrez ${ }^{1}$

\begin{abstract}
Background: Genetic polymorphisms of antioxidant enzymes CAT, GPX, and SOD are involved in the etiology of obesity and its principal comorbidities. The aim of the present study was to analyze the effect of aforementioned SNPs over the output of several variables in people with obesity after a nutritional intervention. The study included 92 Mexican women, which received a dietary intervention by 3 months. Participants were genotyped and stratified into two groups: (1) carriers; mutated homozygous plus heterozygous (CR) and (2) homozygous wild type (WT). A comparison between CR and WT was done in clinical (CV), biochemical (BV), and anthropometric variables (AV), at the beginning and at the end of the intervention.

Results: Participants $(n=92)$ showed statistically significant differences $(p<0.05)$ at the end of the nutritional intervention in several $C V, B V$, and $A V$. However, two kinds of responses were observed after genotyping participants: (A) CR and WT showed statistically significant differences $(p<0.05)$ in several CV, BV, and AV for the SNPs 599C>T GPX1 (rs1050450), 251A>G SOD1 (rs2070424), and - 262C>T CAT (rs1001179). (B) Only CR showed statistically changes $(p<0.05)$ in several CV, BV, and AV for the SNPs - 21A>T CAT (rs7943316) and 47C>T SOD2 (rs4880). The dietary intervention effect was statistically significantly between the polymorphisms of 47C>T SOD2 and BMI, SBP, TBARS, total cholesterol, and C-LCL $(p<0.05)$ and between the polymorphisms of $-21 \mathrm{~A}>\mathrm{T}$ CAT (rs7943316) and SBP, DBP, total cholesterol, and atherogenic index $(p<0.05)$.
\end{abstract}

Conclusion: People with obesity display different response in several CV, BV, and AV after a nutritional intervention, depending on the antioxidant genetic background of SOD and CAT enzymes.

Keywords: Obesity, Genetic polymorphism, SOD, GPX, CAT

\footnotetext{
* Correspondence: cesar.hernandez@ibero.mx

'Departamento de Salud, Universidad Iberoamericana, Prol. Paseo de la

Reforma 880, Col Santa Fe, 01219 México City, Mexico

Full list of author information is available at the end of the article
} 


\section{Background}

Due to changes in lifestyle and eating behaviors of people, the worldwide prevalence of overweight and obesity has increased dramatically in the last decades [1]. The presence of obesity in the population has increased the risk to develop insulin resistance, cardiovascular diseases, metabolic syndrome, type II diabetes, dyslipidemia, cancer, and others $[2,3]$. If an important decrement in the prevalence of overweight and obesity is not achieved, the medical care for such pathologies will far exceed the technical and economic capacity of the health systems in the following years [2-4].

The multifactorial etiology of obesity involves a complex interaction between environment, feeding, physical activity, culture, and genetic factors $[5,6]$. Until now, the initial strategy to control the obesogenic process in a person is to reduce the caloric intake and to increase the energetic expenditure by means of physical activity. However, due to genetic background of diverse singlenucleotide polymorphisms (SNPs), evidence in the literature has shown a different response for people with obesity or associated obesity diseases under a caloric restriction program to modify body composition [7], peripheral lipid concentration [8], blood pressure [9], and insulin resistance [10].

In this sense, SNPs of antioxidant enzymes as catalase $(-262 \mathrm{C}>\mathrm{T}$ CAT, rs1001179, and $-21 \mathrm{~A}>\mathrm{TCAT}$, rs7943316), superoxide dismutase $(-251 \mathrm{~A}>\mathrm{G}$ SOD1, rs2070424, and 47C>T SOD2, rs4880), and glutathione peroxidase (599C>T GPX1, rs1050450) have been identified in coding and regulatory untranslated regions of the gene, which affect the net activity of the enzymes [11-14]. These enzymes work as a key factor to avoid the appearance of oxidative stress condition, inactivating the generation and propagation of endogenous free radicals produced by the cell metabolism [15].

The oxidative stress condition plays an important role in the etiology of the principal comorbidities of obesity. That condition appears when an imbalance of pro-oxidant systems overtakes the antioxidant defense. Diverse mechanisms increase the generation of free radicals in people with obesity as hyperleptinemia, endothelial reactive oxygen species production, chronic inflammation, elevated tissue lipid levels, hyperglycemia, and inadequate antioxidants intake $[16,17]$.

The genetic characteristics of people have been identified as a pivotal factor involved in the etiology of metabolic pathologies as obesity. Several SNPs of CAT, GPX, and SOD have been associated with obesity and its principal comorbidities [18-25]. Our research group previously identified an association with obesity for the SNPs 599C $>$ T GPX1 (rs1050450) and - 251A>G SOD1 (rs2070424). For the SNPs $-21 \mathrm{~A}>\mathrm{T}$ CAT (rs7943316), $-262 \mathrm{C}>\mathrm{T}$ CAT (rs1001179), and 47C>T SOD2 (rs4880), we identified differences between people with obesity CR (homozygous plus heterozygous) of mutated allele, and obese WT people, with respect to anthropometric and clinical variables in a cross-sectional study [26, 27].

The aim of the present work was to assess the impact of the five before mentioned SNPs of CAT, GPX, and SOD, with respect to changes on anthropometric, clinical, and biochemical variables, in a population with obesity after a nutritional intervention of energy restriction by 3 months, with the intention to identify candidate genes which could be included in the followup, evolution and prognosis of obesogenic process, and its main comorbidities.

\section{Methods}

\section{Subjects and dietary intervention}

The study included women with obesity who attended to the Nutrition Clinic of Universidad Iberoamericana in Mexico City to receive nutritional care. All subjects were from a low-income community from Mexico City. The inclusion criteria required a minimum age limit for participants of 18 and a maximum of 65 years of age, no history of eating disorders, thyroid disease, infectious disease, autoimmunity, allergies, non-smokers, and no history of consumption of antioxidant supplements within the past 6 months. Participants with previous diagnosis of diabetes, dyslipidemia, hypertension, or metabolic syndrome diagnostic were not included in the study.

Total energy intake was estimated by a food record method (24-h dietary recalls) over three non-consecutive days including a weekend or a holiday [28]. All the participants received an individual nutritional intervention that included an energy restriction of $500 \mathrm{kcal}$, with a nutrient distribution of $50 \%$ carbohydrates, $25 \%$ protein, and $25 \%$ fat with a fiber intake of at least $25 \mathrm{~g} /$ day, with the strict indication to walk at a "brisk pace" by 30 min per day. The participants enrolled in the study assisted the Nutrition Clinic every 2 weeks for a period of 3 months to check the progress of the dietary intervention and to receive coaching. They received a manual to record their adherence to the nutritional intervention and physical activity. Only participants with an adherence of at least $90 \%$ to the physical and nutritional intervention were included in the analysis.

\section{Determination of antioxidants consumption frequency and total energy expenditure}

A food frequency questionnaire validated by the Mexican National Institute of Public Health was applied to assess the antioxidant intake of participants in the first visit to the Nutrition Clinic [29]. Indirect calorimetry method using a CardioCoach metabolic monitor 9002-CO2 
(KORR Medical Technologies, Salt Lake City, Utah) was used to evaluate the resting metabolic rate. Total energy expenditure was predicted as RMR times physical activity level [30].

\section{Identification of polymorphisms of CAT, GPX, and SOD by PCR-RFLP method}

The conditions, primers sequences, and identification of WT and mutated alleles of the five genetic polymorphisms have been described previously [26, 27].

\section{Determination of glucose, lipids, and thiobarbituric acid reactive substances (TBARS) in peripheral plasma}

A sample of peripheral fasting blood was collected before and after the dietary intervention to assess the biochemical markers. The concentration of glucose (GC), total cholesterol (TC), LDL cholesterol (LDL-C), HDL cholesterol (HDL-C), and triglycerides (TG) was determined by Alere-Cholestec LDX System (Alere, San Diego, California). The lipid peroxidation state of peripheral plasma of each participant was determined by TBARS technique [31].

\section{Statistical analysis}

Data were tested for normal distribution before statistical procedures were performed. Non-normally distributed data were log transformed to reduce skewness. Two-way ANOVA with replication was used to analyze the intervention effect between polymorphism and the dependent variables over the period of time (beginning and the end of the nutritional intervention)-two groups (WT and CR subjects) for each polymorphism-analyzing the interaction between period and group. Differences between the beginning and the end of nutritional intervention within groups were assessed by the paired $t$ test for parametric data or Wilcoxon signed-rank test for non-parametric data. Differences between groups (WT and CR) before and after the intervention were compared using a twosample $t$ test test for parametric data or Mann-Whitney $U$ test for non-parametric data.

In order to explore whether other variables could potentially affect the results of the study, multivariate analyses were carried out taking the variables related to the response of the dietary intervention as dependent variables, the SNPs showing a statistically significant interaction (observed in the two-way ANOVA with replication analysis) as independent variable and controlling for age, BMI, and the other SNPs of interest. Different models with adjustments were used for multivariate analyses: model 1 was adjusted for $-21 \mathrm{~A}>\mathrm{T}$ CAT (rs7943316) or $47 \mathrm{C}>\mathrm{T}$ SOD2 (rs4880); model 2 was adjusted for age and BMI; model 3 was adjusted for $21 \mathrm{~A}>\mathrm{T}$ CAT (rs7943316) or 47C $>\mathrm{T}$ SOD2 (rs4880), age, and BMI (variables in models 1 and 2); and model 4 was adjusted for variables in model 3 plus the other explored SNPs (599C $>$ T GPX1 (rs1050450), - 251A $>$ G SOD1 (rs2070424), and $-262 \mathrm{C}>\mathrm{T}$ CAT (rs1001179). SPSS version 21 for Windows was used to do all the statistical analysis; a $p<0.05$ was accepted as a significant statistical difference.

\section{Results}

The study included 153 women with obesity with a mean age of $40 \pm 13$ years from a low-income community located in Mexico City at the beginning of the dietary intervention. However, only 92 women (age $40 \pm 9.2$ ) were included in the analysis of the data since 61 (39.8\%) women did not have enough adherence to the trial (less than 90\%).

With the intention of identifying if possible changes observed in subjects at the end of the study could be influenced by differences in feeding habits, consumption of antioxidants and pro-oxidants was assessed during the first visit to the Nutrition Clinic. Participants were stratified into two groups by their genotype. One group was constituted by CR of the mutated allele (homozygous plus heterozygous), and the other group was of individuals homozygous for the WT allele; this classification was done by each one of the five SNP studied (data not shown).

The results showed very few differences between the consumption of antioxidants (zinc, copper, manganese, selenium, and vitamins A, C, and E) and pro-oxidants (total fat, saturated fat, cholesterol, total carbohydrate, sucrose, and fructose) by group genotype. Only three differences $(p<0.05)$ in antioxidants consumption were observed which represent just the $4.2 \%$ of the total of possible combinations $(n=70)$ from 10 genotypes (two groups for each SNP) and 7 oligoelements studied. For the case of pro-oxidants, only seven differences $(p<0.05)$ were identified $(11.6 \%)$ of the total of possible combination $(n=60)$ of 6 molecules and 10 genotypes reported.

On the other hand, a statistically significant $(p<0.05)$ improvement in the markers as weight (WG), body mass index (BMI), waist circumference (WC), GC, TG, TC, LDL-C, HDL-C, atherogenic index (AI), systolic (SBP), and diastolic blood pressure (DBP) was observed after 3 months of the trial in the participants; body fat (BF) and visceral fat (VF) did not show any statistical difference (Table 1).

\section{Response to nutritional intervention of participants stratified by genotype of CAT, GPX, and SOD}

When the participants were stratified by CR and WT by each SNP studied, the results showed two patterns of response. The first observed pattern was a similar response of both groups (CR and WT), with respect to the changes observed at the end of the nutritional 
Table 1 Effect of the 3-month dietary intervention on biochemical, clinical, and anthropometric variables on participants

\begin{tabular}{|c|c|c|c|}
\hline Variables & Pre-intervention $(n=92)$ & Post-intervention $(n=92)$ & $p$ value \\
\hline$\overline{\text { Weight }(\mathrm{kg})}$ & $91.9 \pm 18.384 .8$ & $86.4 \pm 1584.4$ & $<0.031^{a}$ \\
\hline $\mathrm{BMI}\left(\mathrm{kg} / \mathrm{m}^{2}\right)$ & $34.9 \pm 4.433 .7$ & $31.9 \pm 4.2530 .4$ & $<0.001^{\mathrm{a}}$ \\
\hline El (Kcal/day) & $1978 \pm 3261978$ & $1926 \pm 3161840$ & 0.320 \\
\hline Waist (cm) & $96.5 \pm 11.395 .3$ & $92.2 \pm 10.292 .3$ & $<0.001^{\mathrm{b}}$ \\
\hline WHR & $0.79 \pm 0.140 .81$ & $0.80 \pm 0.130 .78$ & 0.960 \\
\hline Body fat (\%) & $44.5 \pm 7.642 .8$ & $40.8 \pm 8.441 .8$ & 0.100 \\
\hline Visceral fat $\left(\mathrm{cm}^{2}\right)$ & $173 \pm 47,147.9$ & $157 \pm 49,142.9$ & 0.100 \\
\hline $\mathrm{SBP}(\mathrm{mgHg})$ & $124 \pm 9.7120$ & $119 \pm 12.5121$ & $<0.001^{\mathrm{a}}$ \\
\hline $\mathrm{DBP}(\mathrm{mgHg})$ & $86.1 \pm 10.384$ & $76.5 \pm 7.976 .5$ & $<0.001^{\mathrm{a}}$ \\
\hline TBARS (mg/dl) & $1.39 \pm 0.571 .31$ & $1.03 \pm 0.431 .07$ & $<0.001^{\mathrm{a}}$ \\
\hline Glucose (mg/dl) & $123 \pm 66.3101$ & $108 \pm 26.895 .9$ & $<0.001^{\mathrm{a}}$ \\
\hline Triglycerides (mg/dl) & $154 \pm 38.3156$ & $151 \pm 57.5150$ & $0.003^{\mathrm{a}}$ \\
\hline Total cholesterol (mg/dl) & $177 \pm 44.8163$ & $154 \pm 36.5152$ & $<0.001^{\mathrm{a}}$ \\
\hline $\mathrm{HDL}-\mathrm{C}(\mathrm{mg} / \mathrm{dl})$ & $42.4 \pm 12.743$ & $43.6 \pm 12.243$ & 0.400 \\
\hline $\mathrm{LDL}-\mathrm{C}(\mathrm{mg} / \mathrm{dl})$ & $119 \pm 48.1115 .3$ & $94.9 \pm 35.788 .4$ & $<0.001^{a}$ \\
\hline Atherogenic index & $4.52 \pm 1.734 .19$ & $3.96 \pm 1.493 .40$ & $0.028^{\mathrm{a}}$ \\
\hline
\end{tabular}

Data show: mean $\pm S D$ median. $B M I$ body mass index, El daily energy intake, WHR waist-hip ratio, SBP systolic blood pressure, $D B P$ diastolic blood pressure, TBARS thiobarbituric acid reactive substances, $H D L-C$ high-density lipoprotein, $L D L-C$ low-density lipoprotein

ailcoxon signed-ranks test was used to compare groups

baired $t$ test was used to compare groups

intervention for the SNPs 599C>T GPX1 (rs1050450), $-251 \mathrm{~A}>\mathrm{G}$ SOD1 (rs2070424), and $-262 \mathrm{C}>\mathrm{T}$ CAT (rs1001179).

For the SNP 599C>T GPX1 (rs1050450), CR and WT showed statistical differences $(p<0.05)$ in five variables, BMI, SBP, TBARS, GLU, and LDL-C, when comparing the response before and after the dietary intervention within groups. In the case of the WT, they showed a statistically significant difference in the concentration of TG at the end of the intervention, while for CR, a statistically significant difference in AI and DBP was observed at the end of the intervention. A two-way ANOVA with replication analysis was performed (Table 2), finding a statistically significant interaction $(F=21.19 ; p<0.001)$ between the gene polymorphisms and DBP.

A similar pattern of response was observed in the SNP - 251A>G SOD1 (rs2070424), in which both CR and WT showed a statistically significant $(p<0.05)$ in seven variables BMI, SBP, DBP, TBARS, GC, TC, and LDL-C at the end of the nutritional intervention. Only a statistically significant interaction $(F=8.88 ; p=0.004)$ was found between the gene polymorphisms and SBP (Table 3 ).

In the case of the polymorphism $-262 \mathrm{C}>\mathrm{T}$ CAT (rs1001179), five variables showed a statistically significant difference between the beginning and the end of the dietary intervention in both CR and WT: BMI, SBP, DBP, TBARS, and GC. When the interaction between the gene polymorphisms and the variables of interest was analyzed using the two-way ANOVA with replication analysis, a statistically significant interaction was observed in three variables. The first statistically significant interaction was between the gene polymorphisms and SBP $(F=7.13 ; p=0.009)$, in which $\mathrm{CR}$ and WT response showed a statistically significant difference $(p<0.05)$ at the end of the intervention. A statistically significant interaction was found between TC and gene polymorphisms $(F=4.37, p=0.039)$, but only in the $\mathrm{CR}$ a statistically significant difference was observed at the end of the intervention. Finally, the LDL-C variable showed an interaction $(F=22.96, p<0.001)$ with the gene polymorphisms, but only the WT showed a statistically significant difference at the end of the dietary intervention (Table 4).

The other pattern of change was related to the statistically significant difference in several clinical, anthropometric, and clinical variables between the beginning and the end of the dietary intervention only in CR, for the SNPs $-21 \mathrm{~A}>\mathrm{T}$ CAT (rs7943316) and $47 \mathrm{C}>\mathrm{T}$ SOD2 (rs4880).

For the case of the SNP - 21A>T CAT (rs7943316) CR and WT showed a statistically significant difference at the end of the intervention in four variables BMI, DBP, GC, and LDL-C. When analyzing the interaction of the polymorphism with the aforementioned variables through the two-way ANOVA with replication, a statistically significant interaction was observed between the DBP variable and the gene polymorphisms $(F=10.37, p=0.002)$. A statistically 
Table 2 Effect of the dietary intervention on participants stratified by 599 C>T GPX1 (rs1050450) polymorphisms and interaction between period and group

\begin{tabular}{|c|c|c|c|c|c|c|}
\hline \multicolumn{7}{|l|}{ 599C>T GPX1 (rs1050450) } \\
\hline & & \multirow[b]{2}{*}{ CC $(n=36)$} & \multirow[b]{2}{*}{$C T+\Pi(n=56)$} & \multirow[b]{2}{*}{$p^{1}$} & \multicolumn{2}{|c|}{ Interaction } \\
\hline & & & & & $\bar{F}$ & $p^{2}$ \\
\hline \multirow[t]{2}{*}{$\mathrm{BMI}\left(\mathrm{kg} / \mathrm{m}^{2}\right)$} & Before & $33 \pm 531$ & $35 \pm 533$ & 0.001 & 0.68 & 0.412 \\
\hline & After & $30 \pm 330^{a^{* *}}$ & $33 \pm 432^{* * *}$ & 0.003 & & \\
\hline \multirow[t]{2}{*}{$\mathrm{SBP}(\mathrm{mgHg})$} & Before & $120 \pm 9120$ & $124 \pm 10,120$ & 0.117 & 0.17 & 0.684 \\
\hline & After & $114 \pm 13120^{a^{* *}}$ & $119 \pm 13120^{\mathrm{a}^{* *}}$ & 0.049 & & \\
\hline \multirow[t]{2}{*}{$\mathrm{DBP}(\mathrm{mgHg})$} & Before & $85 \pm 1479$ & $88 \pm 8.988$ & 0.375 & 21.19 & $<0.001$ \\
\hline & After & $77 \pm 8.475$ & $79 \pm 7.179^{\mathrm{a}^{* *}}$ & 0.011 & & \\
\hline \multirow[t]{2}{*}{ TBARS (mg/dl) } & Before & $1.61 \pm 0.611 .40$ & $1.34 \pm 0.611 .32$ & 0.031 & 2.71 & 0.103 \\
\hline & After & $1.08 \pm 0.421 .06^{\mathrm{a}^{* *}}$ & $1.01 \pm 0.451 .02^{\mathrm{a}^{*}}$ & 0.611 & & \\
\hline \multirow[t]{2}{*}{ Glucose (mg/dl) } & Before & $127 \pm 73,104$ & $126 \pm 68,105$ & 0.600 & 0.79 & 0.374 \\
\hline & After & $102 \pm 2999^{a^{* *}}$ & $105 \pm 2599^{a^{* *}}$ & 0.990 & & \\
\hline \multirow[t]{2}{*}{ Total cholesterol (mg/dl) } & Before & $176 \pm 57,161$ & $169 \pm 34,169$ & 0.489 & 1.11 & 0.295 \\
\hline & After & $159 \pm 43,152$ & $150 \pm 27150^{b^{* *}}$ & 0.384 & & \\
\hline \multirow[t]{2}{*}{ LDL-C (mg/dl) } & Before & $117.9 \pm 52.1107$ & $126.5 \pm 50.4125$ & 0.174 & 0.01 & 0.914 \\
\hline & After & $93.7 \pm 35.889^{\mathrm{a}^{* *}}$ & $102.6 \pm 38.995 .5^{\mathrm{a}^{* *}}$ & 0.347 & & \\
\hline \multirow[t]{2}{*}{ Triglycerides (mg/dl) } & Before & $163.1 \pm 32.3157$ & $154.8 \pm 39.2147$ & 0.153 & 0.05 & 0.822 \\
\hline & After & $161 \pm 73.5156^{\mathrm{a}^{*}}$ & $149 \pm 48.7138$ & 0.660 & & \\
\hline \multirow[t]{2}{*}{ Atherogenic index } & Before & $4.5 \pm 3.34$ & $4.1 \pm 1.14 .3$ & 0.955 & 2.52 & 0.116 \\
\hline & After & $3.8 \pm 1.53 .5$ & $3.6 \pm 1.43 .3^{\mathrm{a}^{*}}$ & 0.033 & & \\
\hline
\end{tabular}

Data show: mean $\pm S D$ median, $B M I$ body mass index, SBP systolic blood pressure, DBP diastolic blood pressure, TBARS thiobarbituric acid-reactive substances, $L D L-C$ low-density lipoprotein. $p^{1} p$ value of the comparison between groups (wild type and carriers) before and after the intervention. Mann-Whitney $U$ test or two-sample $t$ test was used to compare groups. $p^{2} p$ value of the interaction. Interaction was calculated with two-way ANOVA with replication ${ }^{*} p<0.05,{ }^{* *} p<0.001$

ailcoxon signed-rank test was used to compare between before and after the intervention in the same group

${ }^{\mathrm{b}}$ Paired $t$ test was used to compare between before and after the intervention in the same group

significant difference $(p<0.05)$ was observed only in the $-21 \mathrm{~A}>\mathrm{T}$ CAT (rs7943316) $\mathrm{CR}$ in three variables at the end of the nutritional intervention, in which a statistically significant interaction was found with the genetic polymorphism, SBP $(F=4.48, p=0.037)$, TC $(F=13.26, \quad p<0.001), \quad$ and $\mathrm{AI} \quad(F=5.35, \quad p=0.023)$ (Table 4).

For the case of the SNP 47C $>\mathrm{T}$ SOD2 (rs4880) CR and WT showed a statistically significant difference at the end of the intervention in three variables BMI, DBP, and GC. When analyzing the interaction of the gene polymorphisms with the aforementioned variables using the two-way ANOVA with replicates, a statistically significant interaction was found with the BMI variable $(F$ $=105.37, p<0.001)$. A statistically significant difference $(p<0.05)$ was observed in four variables in the CR at the end of the nutritional intervention. Those variables also showed a statistically significant interaction with the gene polymorphisms: SBP $(F=4.66, p=0.034)$, TBARS $(F=6.59, p=0.012)$, TC $(F=7.87, p=0.006)$, and LDL-C $(F=10.95, p=0.001)$ (Table 3).
In the multivariate analyses, the statistically significant differences observed between WT and CR of $47 \mathrm{C}>\mathrm{T}$ SOD2 (rs4880) after the intervention were on IMC in model $4(p=0.029)$, on TBARS in model $1(p=0.023)$, model $3(p=0.017)$, and model $4(p=0.028)$; between WT and CR of $-21 \mathrm{~A}>\mathrm{T}$ CAT (rs7943316) were on DBP in model $2(p=0.001)$, model $3(p=0.002)$, and model $4(p=0.020)$.

\section{Discussion}

The present work addresses the participation of five SNPs of the principal antioxidant enzymes, from a nutrigenetic point of view in people living with obesity. These five particular SNPs were selected due to their role in the etiology of obesity and its principal comorbidities, worldwide and in our population.

The work started with 153 mestizo Mexican women from the central plateau of Mexico; nonetheless, only 92 women finished the trial with an adherence equal or more than $90 \%$. Several reasons account the desertion; however, two of these reasons (non-exclusive) were the 
Table 3 Effect of the dietary intervention on participants stratified by - 251 A>G SOD1 (rs2070424) and 47C>T SOD2 (rs4880) polymorphisms, and interaction between period and group

\begin{tabular}{|c|c|c|c|c|c|c|c|c|c|c|c|}
\hline & \multicolumn{5}{|c|}{$-251 \mathrm{~A}>\mathrm{G}$ SOD1 (rs2070424) } & \multirow[b]{3}{*}{$C C(n=30)$} & \multicolumn{4}{|c|}{ 47C>T SOD2 (rs4880) } \\
\hline & & \multirow[b]{2}{*}{$\mathrm{AA}(n=53)$} & \multirow[b]{2}{*}{$\mathrm{AG}+\mathrm{GG}(n=39)$} & \multirow[b]{2}{*}{$p^{1}$} & \multicolumn{2}{|c|}{ Interaction } & & \multirow[b]{2}{*}{$\mathrm{TC}+\mathrm{TT}(n=62)$} & \multirow[b]{2}{*}{$p^{1}$} & \multicolumn{2}{|c|}{ Interaction } \\
\hline & & & & & $F$ & $p^{2}$ & & & & $F$ & $p^{2}$ \\
\hline \multirow[t]{2}{*}{ BMI $\left(\mathrm{kg} / \mathrm{m}^{2}\right)$} & Before & $34 \pm 4.933$ & $32 \pm 4.530$ & 0.021 & 0.32 & 0.570 & $35 \pm 4.132$ & $34 \pm 4.833$ & 0.047 & 105.37 & $<0.001$ \\
\hline & After & $33 \pm 4.231^{a^{* *}}$ & $31 \pm 3.830^{\mathrm{a}^{* *}}$ & 0.009 & & & $32 \pm 531^{1^{*}}$ & $32 \pm 4.131^{\mathrm{a}^{* *}}$ & 0.105 & & \\
\hline \multirow[t]{2}{*}{$\mathrm{SBP}(\mathrm{mgHg})$} & Before & $124 \pm 9.8120$ & $120 \pm 8.9119$ & 0.082 & 8.88 & 0.004 & $122 \pm 12,121$ & $123 \pm 7.7121$ & 0.736 & 4.66 & 0.034 \\
\hline & After & $117 \pm 11120^{a^{* *}}$ & $113 \pm 13120^{a^{*}}$ & 0.759 & & & $120 \pm 13,120$ & $113 \pm 12120^{* * *}$ & 0.594 & & \\
\hline \multirow[t]{2}{*}{$\mathrm{DBP}(\mathrm{mgHg})$} & Before & $85 \pm 1084$ & $89 \pm 990$ & 0.008 & 2.23 & 0.139 & $85 \pm 9.885$ & $87 \pm 1085$ & 0.461 & 0.05 & 0.824 \\
\hline & After & $78 \pm 7.976^{\mathrm{a}^{* *}}$ & $77 \pm 6.879^{\mathrm{a}^{* *}}$ & 0.489 & & & $78 \pm 9.178^{\mathrm{a}^{* *}}$ & $77 \pm 6.476^{\mathrm{a}^{* *}}$ & 0.320 & & \\
\hline \multirow[t]{2}{*}{ TBARS (mg/dl) } & Before & $1.41 \pm 0.641 .23$ & $1.48 \pm 0.571 .41$ & 0.429 & 0.26 & 0.614 & $1.30 \pm 0.421 .20$ & $1.42 \pm 0.651 .30$ & 0.443 & 6.59 & 0.012 \\
\hline & After & $1.09 \pm 0.421 .02^{\mathrm{a}^{* *}}$ & $1.11 \pm 0.51 .09^{\mathrm{a}^{* *}}$ & 0.446 & & & $1.18 \pm 0.491 .20$ & $1.00 \pm 0.471 .05^{\mathrm{a}^{* *}}$ & 0.036 & & \\
\hline \multirow[t]{2}{*}{ Glucose (mg/dl) } & Before & $135 \pm 82,105$ & $104 \pm 25,103$ & 0.254 & 1.47 & 0.229 & $127 \pm 80,101$ & $127 \pm 60,102$ & 0.223 & 0.31 & 0.576 \\
\hline & After & $107 \pm 32100^{a * *}$ & $98 \pm 9.597^{\mathrm{a}^{* *}}$ & 0.040 & & & $106 \pm 3292^{\mathrm{a}^{* *}}$ & $101 \pm 1996^{\mathrm{a}^{* *}}$ & 0.009 & & \\
\hline \multirow{2}{*}{$\begin{array}{l}\text { Total cholesterol } \\
(\mathrm{mg} / \mathrm{dl})\end{array}$} & Before & $174 \pm 51,166$ & $173 \pm 38,169$ & 0.613 & 0.85 & 0.358 & $170 \pm 35,164$ & $174 \pm 43,175$ & 0.747 & 7.87 & 0.006 \\
\hline & After & $153 \pm 40146^{\mathrm{a}^{* *}}$ & $156 \pm 30153^{\mathrm{a}^{*}}$ & 0.265 & & & $156 \pm 36,144$ & $154 \pm 39153^{a^{* *}}$ & 0.164 & & \\
\hline \multirow[t]{2}{*}{ LDL-C (mg/dl) } & Before & $118 \pm 52,105$ & $125 \pm 41,122$ & 0.275 & 0.00 & 0.954 & $108 \pm 5290$ & $124 \pm 43,123$ & 0.066 & 10.95 & 0.001 \\
\hline & After & $93 \pm 3684^{a^{* *}}$ & $94 \pm 3192^{\mathrm{a}^{* *}}$ & 0.445 & & & $88 \pm 3279$ & $96 \pm 3594^{\mathrm{a}^{* *}}$ & 0.527 & & \\
\hline \multirow[t]{2}{*}{ Triglycerides (mg/dl) } & Before & $161 \pm 42,152$ & $149 \pm 26,148$ & 0.068 & 3.53 & 0.064 & $167 \pm 43,159$ & $151 \pm 36,148$ & 0.127 & 0.00 & 0.961 \\
\hline & After & $167 \pm 69,158$ & $132 \pm 43122^{\mathrm{a}^{*}}$ & 0.001 & & & $168 \pm 59,150$ & $154 \pm 59,146$ & 0.148 & & \\
\hline \multirow[t]{2}{*}{ Atherogenic index } & Before & $4.7 \pm 2.34 .1$ & $4.2 \pm 1.04 .2$ & 0.853 & 3.30 & 0.073 & $4.4 \pm 2.64 .2$ & $4.5 \pm 1.64 .1$ & 0.543 & 2.49 & 0.118 \\
\hline & After & $4.0 \pm 1.53 .5$ & $3.9 \pm 1.33 .8$ & 0.138 & & & $4.3 \pm 1.73 .6$ & $3.9 \pm 1.43 .4^{\mathrm{a}^{*}}$ & 0.074 & & \\
\hline
\end{tabular}

Data show: mean $\pm S D$ median, $B M I$ body mass index, $S B P$ systolic blood pressure, DBP diastolic blood pressure, TBARS thiobarbituric acid-reactive substances, $L D L-C$ low-density lipoprotein. $p^{1} p$ value of the comparison between groups (wild type and carriers) before and after the intervention. Mann-Whitney $U$ test or two-sample $t$ test was used to compare groups. $p^{2} p$ value of the interaction. Interaction was calculated with two-way ANOVA with replication ${ }^{*} p<0.05,{ }^{* *} p<0.001$

Wilcoxon signed-rank test was used to compare between before and after the intervention in the same group

${ }^{\mathrm{b}}$ Paired $t$ test was used to compare between before and after the intervention in the same group

principal ones: First, the inability of the participants to have an adequate adherence to the nutritional intervention at home, lack of support from their families to implement new healthy behaviors, and lack of possibility for the participants to develop two different menus due to cost and time. Secondly, the inability to perform the 30 min of daily physical activity due to a lack of time (work, chores, commute) or not having an adequate place to exercise (overcrowding or unsafe conditions). These findings on the cultural and environmental conflicts are not new; however, we wish to remark them because they are very important aspects present in people from low-income communities in developing countries like ours, which promote the obesogenic problem.

When we analyze the response of total of participants $(n=92)$ that finished the intervention, they showed good results in regard to the biochemical, anthropometric, and clinical variables studied. These results were obtained by means of a nutritional intervention together with an accessible physical activity recommendation (walk at a "brisk pace" by $30 \mathrm{~min}$ ) since exercise has been demonstrated to improve the metabolic profile in people with obesity [32]. This improvement is directly associated with the reduction in body fat especially visceral fat since the visceral fat by means of proinflammation and oxidative stress conditions plays an important role in the appearance of obesity comorbidities as diabetes type II, resistance insulin, metabolic syndrome, dyslipidemia, etc. [33]. Furthermore, a body weight variation due to an energy-restricted diet in obese subject has been correlated with gene expression responses in processes of energy metabolism (oxidative phosphorylation, mitochondrion, generation of precursor metabolites and energy, regulation of lipid metabolism), focal adhesion and inflammation ( $T$ cell activation) in adipose tissue [34].

On the other hand, two kinds of responses were observed from the stratification of participant's genotype and by evaluating their response by the end of the trail. The first one was identified as the capacity of the CR and the WT of SNPs 599C>T GPX1 (rs1050450), $251 \mathrm{~A}>\mathrm{G}$ SOD1 (rs2070424), and $-262 \mathrm{C}>\mathrm{T}$ CAT 
Table 4 Effect of the dietary intervention on participants stratified by - 21A>T CAT (rs7943316) and - 262C>T CAT (rs1001179) polymorphisms, and interaction between period and group

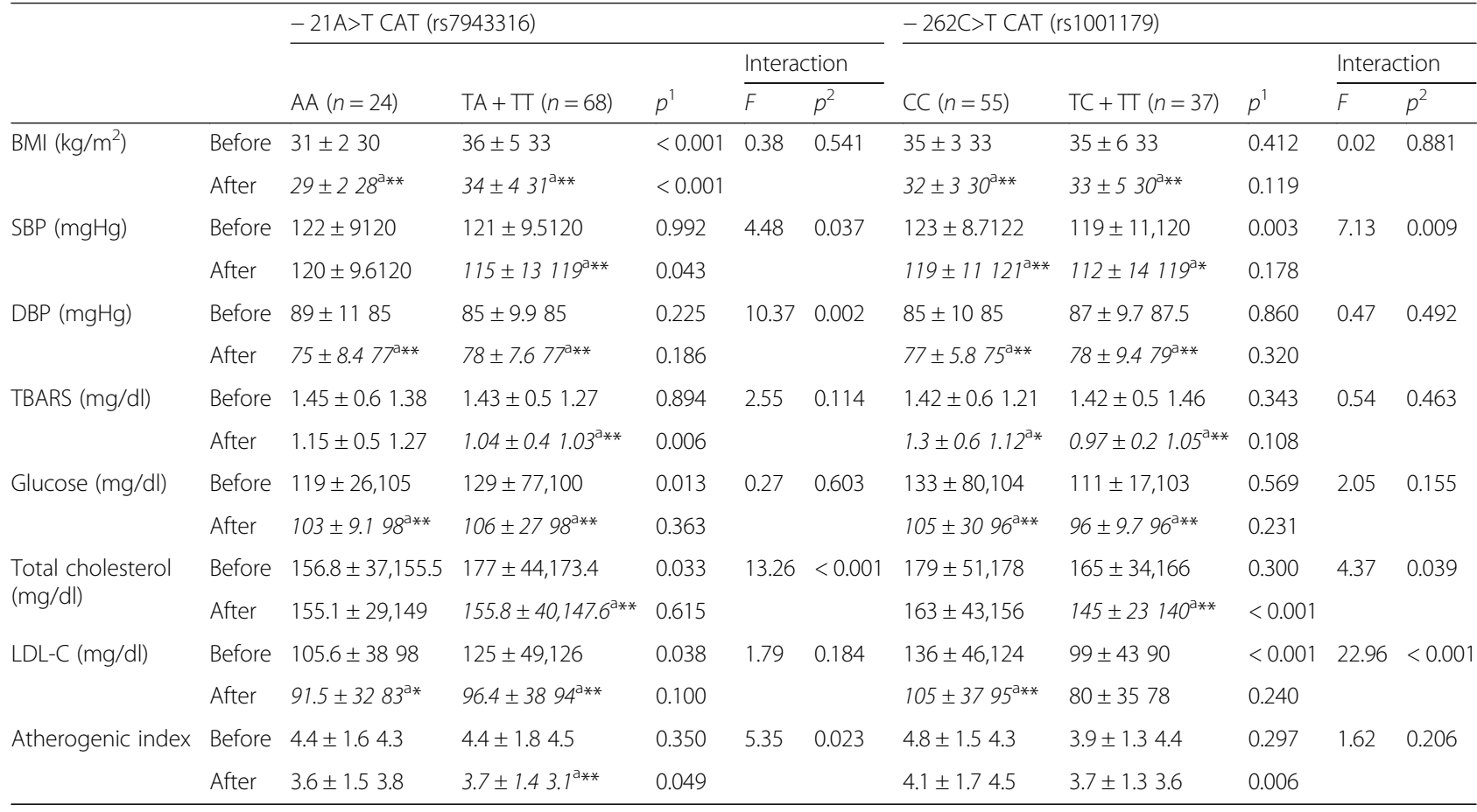

Data show: mean $\pm S D$ median, $B M I$ body mass index, $S B P$ systolic blood pressure, $D B P$ diastolic blood pressure, $T B A R S$ thiobarbituric acid reactive substances, $L D L$ low density lipoprotein. $p^{1} p$ value of the comparison between groups (wild type and carriers) before and after the intervention. Mann-Whitney $U$ test or twosample $t$ test was used to compare groups. $p^{2} p$ value of the interaction. Interaction was calculated with two-way ANOVA with replication $p<0.05,{ }^{* *} p<0.001$

ailcoxon signed-rank test was used to compare between before and after the intervention in the same group

${ }^{b}$ Paired $t$ test was used to compare between before and after the intervention in the same group

(rs1001179) to respond in a similar way after the nutritional intervention.

The second kind of response was the capacity of only the CR of SNPs $-21 \mathrm{~A}>\mathrm{T}$ CAT (rs7943316) and 47C $>\mathrm{T}$ SOD2 (rs4880) to get statistical changes in several variables at the end of the nutritional intervention. The response mentioned before of both SNPs by CR is notable, as the polymorphism - 21A>T CAT (rs7943316) showed a statistically significant interaction with four variables (SBP, DBP, TC, and $\mathrm{AI}$ ), while the polymorphism $47 \mathrm{C}>\mathrm{T}$ SOD2 (rs4880) showed a statistically significant interaction with five variables (BMI, SBP, TBARS, TC, and AI). Two of these last variables were common for both polymorphisms (SBP and TC).

We expected that the response of the WT people would be better in general in comparison with mutated $\mathrm{CR}$, but to our surprise, none of the WT groups of the five SNPs displayed this characteristic. In this respect, evidence [35-38] has shown that the mutated allele of several SNPs studied in the present work was associated with more severe complications or comorbidities in people with metabolic disease as diabetes type I and type II. In particular, Ascencio-Montiel et al. [39] identified an association between macroalbuminuria (as a predictor for diabetic nephropathy) in Mexican people with diabetes type II and the homozygous mutated TT genotype of $47 \mathrm{C}>\mathrm{T}$ SOD2 (rs4880).

We do not have an extended explanation related to the superior response shown by CR of SNPs $-21 \mathrm{~A}>\mathrm{T}$ CAT (rs7943316) and 47C >T SOD2 (rs4880). However, CAT is a relevant ubiquitous enzyme that neutralizes the hydrogen peroxide, it is a principal antioxidant cytoplasmic enzyme, and it seems to play an important role in the obesogenic process and in the developments of its comorbidities.

At the functional level, a previous report identified a significant inverse correlation between the activity of plasma erythrocyte enzyme with weight, BMI, plasma insulin, and HOMA in a case study $(n=194)$ and controls $(n=191)$ among Spanish children with obesity [25]. In the same study, the $-21 \mathrm{~A}>\mathrm{T}$ CAT (rs7943316) polymorphism was associated with an increased risk for the development of obesity (OR $=1.38$, CI 95\%, $1-1.91 ; p<0.05)$ as well as the neighbor polymorphisms $-844 \mathrm{~A}>\mathrm{G}$ CAT (rs769214) and $-20 \mathrm{C}>\mathrm{T}$ CAT (rs1049982).

In the molecular field, Saify [40] described for the first time the appearance of a nuclear binding site for the nuclear transcriptional factor PAX-6, when the substitution of adenine to thymine is present in the SNP - 
21A $>\mathrm{T}$ CAT (rs7943316). The PAX-6 is a highly conserved multifunctional transcription factor that takes part actively in the development of the eye and brain, and it has been proposed to bind to the promoter region of CAT gen to regulate its expression. Directly in line with previous data mentioned, Saify et al. [41] identified the mRNA gene expression of CAT from peripheral mononuclear cells stratified by AA, AT, and TT genotype of $-21 \mathrm{~A}>\mathrm{T}$ CAT (rs7943316) polymorphism. A significant positive correlation was observed between the mRNA level expression of CAT by mononuclear cells and the presence of thymine allele. Thus, a higher antioxidant CAT enzyme capacity could be involved in the better response shown by participant $\mathrm{CR}$ of $\mathrm{T}$ allele in our study.

For the case of $47 \mathrm{C}>\mathrm{T}$ SOD2 (rs4880), the argument of a higher enzyme capacity is not possible because of the presence of the thymine allele in CR of this SNP, abrogates the enzymatic activity of SOD2 around 30-40\% [21]. Though, inconsistent results have been shown related to the interaction between the SNP 47C $>$ T SOD2 (rs4880) and antioxidant status; likewise, dietary factors can modulate its activity $[15,42]$.

A multivariate analysis adjusted for different variables was carried out with the aim to observe the effect of the SNPs of interest in the present study on the identified response at the end of the study in the participants (overlapping) as well as other variables such as age and BMI. We identified that in general, there is not relevant overlapping effect since in the case of $-21 \mathrm{~A}>\mathrm{T}$ CAT (rs7943316), in which we identified a statistically significant interaction in four variables between $\mathrm{CR}$ and WT at the end of the intervention (SBP, DBP, TC, AI), we observed a statistically significant value only on DBP in the adjusted models 2,3 , and 4 . While in the case of $47 \mathrm{C}>\mathrm{T}$ SOD2 (rs4880), we identified a statistically significant value in BMI, in the adjusted model 4 , and in TBARS, in the adjusted models 1,3 , and 4 .

In the specific case of model 1 , where we evaluate the participation of the other polymorphism showing a statistically significant interaction in the two-way ANOVA with replication analysis $(-21 \mathrm{~A}>\mathrm{T}$ CAT or 47C $>$ T SOD), we only identified a statistically significant difference between CR and WT in TBARS. This result seems consistent with physiological oxidation-reduction process that the study participants presented at the end of the study since the aforementioned polymorphisms actively participate in the regulation of the cellular redox process.

To our knowledge, this is the first work related to the influence of the five SNPs studied herein on a nutrigenetic study in people with obesity. The limitation of a relatively small number of participants that finished the study is compensated by the homogeneous group of subjects formed. People who finished the intervention showed a high adherence to the nutritional and physical activity maneuver, and they were a non-related mestizo genetic group from a typical low-incoming community of central plateau of Mexico, with fathers and grandfathers born in Mexico.

Although diverse SNPs have been associated worldwide with several metabolic diseases, it is necessary to increase this knowledge on each population because every ethnic group has a specific set of genes implicated in these pathologies, as a result of the own "gene-imprinting" and "gene-transfer," diet, geographic area of habitat, lifestyle, etc. [43, 44].

On the other hand, even if there is a great probability that several SNPs are involved in the observed final physiological response in subjects under a dietary intervention, the SNPs $-21 \mathrm{~A}>\mathrm{T}$ CAT (rs7943316) and $47 \mathrm{C}>\mathrm{T}$ SOD2 (rs4880) reported in the present work could be used in future studies as a genetic tool to improve the treatment of overweight and obesity as well as to identify, trace, and evaluate the risk to develop several comorbidities of obesity.

\section{Conclusion}

The CR of SNPs $-21 \mathrm{~A}>\mathrm{T}$ CAT (rs7943316) and 47C $>\mathrm{T}$ SOD2 (rs4880) are implicated in a better response in anthropometric, clinical, and biochemical markers in comparison with their respective WT group after a nutritional intervention by 3 months. However, the participation of other SNPs related to enzymatic antioxidant defense can be implicated on the results of the present study.

\section{Abbreviations}

Al: Atherogenic index; AV: Anthropometric variables; BMl: Body mass index; BP: Body fat; BV: Biochemical; CAT: Catalase; HDL-C: High-density lipoprotein cholesterol; LDL-C: Low-density lipoprotein cholesterol; CR: Carriers; CV: Clinical variables; DBP: Diastolic blood pressure; GC: Glucose; GPX1: Glutathione peroxidase; SBP: Systolic blood pressure; SNPs: Single nucleotide polymorphisms; SOD: Superoxide dismutase; TBARS: Thiobarbituric acid reactive substances; TC: Total-cholesterol; TG: Triglycerides; VF: Visceral fat; WC: Waist circumference; WG: Weight; WT: Homozygous wild type

\section{Acknowledgements \\ We gratefully acknowledge the team of the Nutrition Clinic and Laboratory of Research of the Health Department of the University for their active participation.}

\section{Funding}

The present work was supported by the "Onceava Convocatoria Para Financiamiento de Proyectos de Investigación" through the Research Direction of Universidad Iberoamericana Ciudad de México.

\section{Availability of data and materials}

The datasets used and/or analyzed during the current study are available from the corresponding author on reasonable request.

\section{Authors' contributions}

CHG designed and directed the protocol, write the manuscript. APC, DRS, and CDG carried out the nutritional intervention. OGC and MBJ analyzed the data. All authors read and approved the final manuscript. 


\section{Ethics approval and consent to participate}

The protocol was reviewed and approved by the Scientific and Ethics Committees of the Universidad Iberoamericana. The subjects were informed about the objectives and goals of the protocol and signed an informed consent when they decided to participate in the study. The study was carried out according to the ethical standards declared in the Declaration of Helsinki.

\section{Consent for publication}

Not applicable.

\section{Competing interests}

The authors declare that they have no competing interests.

\section{Publisher's Note}

Springer Nature remains neutral with regard to jurisdictional claims in published maps and institutional affiliations.

\section{Author details}

'Departamento de Salud, Universidad Iberoamericana, Prol. Paseo de la Reforma 880, Col Santa Fe, 01219 México City, Mexico. ${ }^{2}$ Especialidad en Obesidad y Comorbilidades, Universidad Iberoamericana, Ciudad de México, Mexico. ${ }^{3}$ Departamento de Psicología, Universidad Iberoamericana, Ciudad de México, Mexico.

\section{Received: 28 August 2017 Accepted: 7 December 2017}

\section{Published online: 08 January 2018}

\section{References}

1. Raynor HA, Champagne CM. Position of the academy of nutrition and dietetics: interventions for the treatment of overweight and obesity in adults. J Acad Nutr Diet. 2016;116:129-47.

2. Castro-Ríos A, Nevárez-Sida A, Tiro-Sánchez MT, Wacher-Rodarte N. Triggering factors of primary care costs in the years following type 2 diabetes diagnosis in Mexico. Arch Med Res. 2014:45:400-8.

3. Cefalu WT, Bray GA, Home PD, Garvey WT, Klein S, Pi-Sunyer FX, Hu FB, Raz I, Van Gaal L, Wolfe BM. Advances in the science, treatment, and prevention of the disease of obesity: reflections from a diabetes care editors' expert forum. Diabetes Care. 2015;38:1567-82.

4. de Oliveira ML, Santos LMP, da Silva EN. Direct healthcare cost of obesity in Brazil: an application of the cost-of-illness method from the perspective of the public health system in 2011. PLoS One. 2015;10:e0121160.

5. Bombak AE. The "obesity epidemic": evolving science, Unchanging Etiology Sociology Compass. 2014;8:509-524.

6. Rukh G, Sonestedt E, Melander O, Hedblad B, Wirfält E, Ericson U, Orho-Melander M. Genetic susceptibility to obesity and diet intakes: association and interaction analyses in the Malmö Diet and Cancer Study. Genes Nutr. 2013;8:535-47.

7. Suchánek P, Lánská V, Hubácek JA. Body composition changes in adult females after lifestyle intervention are influenced by the NYD-SP18 variant. Cent Eur J Public Health. 2015;23:19-22.

8. Brahe LK, Ängquist L, Larsen LH, Vimaleswaran KS, Hager J, Viguerie N, Loos RJ, Handjieva-Darlenska T, Jebb SA, Hlavaty P. Influence of SNPs in nutrient-sensitive candidate genes and gene-diet interactions on blood lipids: the DiOGenes study. Br J Nutr. 2013;110:790-6.

9. Chu C, Wang Y, Ren K, Yan D, Guo T, Zheng W, Yuan Z, Mu J. Genetic variants in adiponectin and blood pressure responses to dietary sodium or potassium interventions: a family-based association study. J Hum Hypertens. 2016;30:563-70

10. Black MH, Wu J, Takayanagi M, Wang N, Taylor KD, Haritunians T, Trigo E, Lawrence JM, Watanabe RM, Buchanan TA. Variation in PPARG is associated with longitudinal change in insulin resistance in Mexican Americans at risk for type 2 diabetes. J Clin Endocrinol Metab. 2015;100:1187-95.

11. Kase BA, Northrup H, Morrison AC, Davidson CM, Goiffon AM, Fletcher JM, Ostermaier KK, Tyerman GH, Au KS. Association of copper-zinc superoxide dismutase (SOD1) and manganese superoxide dismutase (SOD2) genes with nonsyndromic myelomeningocele. Birth Defects Res A Clin Mol Teratol. 2012;94:762-9.

12. Crawford A, Fassett RG, Geraghty DP, Kunde DA, Ball MJ, Robertson IK, Coombes JS. Relationships between single nucleotide polymorphisms of antioxidant enzymes and disease. Gene. 2012;501:89-103.
13. Lubos E, Loscalzo J, Handy D. Glutathione peroxidase-1 in health and disease: from molecular mechanisms to therapeutic opportunities. Antioxid Redox Signal. 2011;15:1957-97.

14. Lourdhu Mary A, Nithya K, Isabel W, Angeline T. Prevalence of catalase $(-21 \mathrm{a} / \mathrm{T})$ gene variant in south Indian (Tamil) population. Biomed Res Int 2014; http://dx.doi.org/https://doi.org/10.1155/2014/894237

15. Lei XG, Zhu JH, Cheng WH, Bao Y, Ho YS, Reddi AR, Holmgren A, Arner ES. Paradoxical roles of antioxidant enzymes: basic mechanisms and health implications. Physiol Rev. 2016;96:307-64.

16. Manna P, Jain SK. Obesity, oxidative stress, adipose tissue dysfunction, and the associated health risks: causes and therapeutic strategies. Metab Syndr Relat Disord. 2015;13:423-44.

17. Vincent HK, Taylor AG. Biomarkers and potential mechanisms of obesityinduced oxidant stress in humans. Int J Obes. 2006;30:400.

18. Witzel I, Jelinek HF, Khalaf K, Lee S, Khandoker AH, Alsafar H. Identifying common genetic risk factors of diabetic neuropathies. Front Endocrinol (Lausanne). 2015;6:88.

19. Chen H, Yu M, Li M, Zhao R, Zhu Q, Zhou W, Lu M, Lu Y, Zheng T, Jiang J. Polymorphic variations in manganese superoxide dismutase (MnSOD), glutathione peroxidase-1 (GPX1), and catalase (CAT) contribute to elevated plasma triglyceride levels in Chinese patients with type 2 diabetes or diabetic cardiovascular disease. Mol Cell Biochem. 2012;363:85-91.

20. Duarte T, da Cruz I, Barbisan F, Capelleto D, Moresco R, Duarte M. The effects of rosuvastatin on lipid-lowering, inflammatory, antioxidant and fibrinolytics blood biomarkers are influenced by Val16Ala superoxide dismutase manganesedependent gene polymorphism. Pharmacogenomics J. 2016;16:501-6.

21. Bitarafan F, Khodaeian M, Tabatabaei-Malazy O, Amoli MM. Influencing of antioxidants' gene variants on risk of diabetes mellitus and its complications: a systematic review. Minerva Endocrinol. 2017; https://doi. org/10.23736/S0391-1977.17.02632-3.

22. Zhang Y, Zhang L, Sun D, Li Z, Wang L, Liu P. Genetic polymorphisms of superoxide dismutases, catalase, and glutathione peroxidase in age-related cataract. Mol Vis. 2011;17:2325-32.

23. Perianayagam MC, Liangos O, Kolyada AY, Wald R, MacKinnon RW, Li L, et al. NADPH oxidase p22phox and catalase gene variants are associated with biomarkers of oxidative stress and adverse outcomes in acute renal failure. J Am Soc Nephrol. 2007;18:255-63.

24. Ruperez Al, Gil A, Aguilera CM. Genetics of oxidative stress in obesity. Int J Mol Sci. 2014;15:3118-44.

25. Ruperez Al, Olza J, Gil-Campos M, Leis R, Mesa MD, Tojo R, Canete R, Gil A, Aguilera CM. Are catalase -844A/G polymorphism and activity associated with childhood obesity? Antioxid Redox Signal. 2013;19:1970-5.

26. Hernández Guerrero C, Hernández Chávez P, Martínez Castro N, Parra Carriedo A, García Del Río S, Pérez LA. Glutathione peroxidase-1 Pro200Leu polymorphism (rs1050450) is associated with morbid obesity independently of the presence of prediabetes or diabetes in women from Central Mexico. Nutr Hosp. 2015;32:1516-25.

27. Hernández-Guerrero C, Hernández-Chávez P, Romo-Palafox I, BlancoMelo G, Parra-Carriedo A, Pérez-Lizaur A. Genetic polymorphisms in SOD (rs2070424, rs7880) and CAT (rs7943316, rs1001179) enzymes are associated with increased body fat percentage and visceral fat in an obese population from Central Mexico. Arch Med Res. 2016:47:331-9.

28. The validity of 24-hour dietary recalls. Nutr Rev. 1976;34:310-1. Version of Record online: 2009. https://doi.org/10.1111/j.1753-4887.1976.tb05680.x.

29. Hernández-Avila M, Romieu I, Parra S, Hernández-Avila J, Madrigal H, Willett W. Validity and reproducibility of a food frequency questionnaire to assess dietary intake of women living in Mexico City. Salud Pública Méx. 1998;39:133-40.

30. Craig CL, Marshall AL, Sjostrom M, Bauman AE, Booth ML, Ainsworth BE, Pratt M, Ekelund U, Yngve A, Sallis JF, et al. International physical activity questionnaire: 12-country reliability and validity. Med Sci Sport Exer. 2003;3:1381-95.

31. Estepa V, Rodenas S, Martin MC. Optimización de un método para la determinación de la peroxidación lipídica en suero humano. Anal Real Acad Farm. 2001;67:1-17.

32. Russo A, Pirisinu I, Vacca C, Reginato E, Tomaro ES, Pippi R, Aiello C, Talesa VN, De Feo P, Romani R. An intensive life style intervention reduces circulating oxidized low-density lipoprotein and increases human paraoxonase activity in obese subjects. Obes Res Clin Pract. 2016;629:1-7. 
33. Luna-Luna M, Medina-Urrutia A, Vargas-Alarcón G, Coss-Rovirosa F, VargasBarrón J, Pérez-Méndez Ó. Adipose tissue in metabolic syndrome: onset and progression of atherosclerosis. Arch Med Res. 2015;46:392-407.

34. Pasman W, Erk M, Klöpping W, Pellis L, Wopereis S, Bijlsma S, Hendriks H, Kardinaal A. Nutrigenomics approach elucidates health-promoting effects of high vegetable intake in lean and obese men. Genes Nutr. 2013;8:507-21.

35. Hosseini SM, Boright AP, Sun L, Canty AJ, Bull SB, Klein BE, Klein R, Paterson $A D, D C C T / E D I C$ Research Group. The association of previously reported polymorphisms for microvascular complications in a meta-analysis of diabetic retinopathy. Hum Genet. 2015;134:247-57.

36. Becer E, Clırakoğlu A. Association of the Ala16Val MnSOD gene polymorphism with plasma leptin levels and oxidative stress biomarkers in obese patients. Gene. 2015;568:35-9.

37. Góth L, Nagy T, Kósa Z, Fejes Z, Bhattoa HP, Paragh G, Káplár M. Effects of rs769217 and rs1001179 polymorphisms of catalase gene on blood catalase, carbohydrate and lipid biomarkers in diabetes mellitus. Free Radic Res. 2012:46:1249-57.

38. Jones D, Prior S, Tang T, Bain S, Hurel S, Humphries S, Stephens J. Association between the rs 4880 superoxide dismutase 2(C>T) gene variant and coronary heart disease in diabetes mellitus. Diab Res Clinical Pract. 2010;90:196-201.

39. Ascencio-Montiel Ide J, Parra EJ, Valladares-Salgado A, Gómez-Zamudio JH, Kumate-Rodriguez J, Escobedo-de-la-Peña J, Cruz M. SOD2 gene Val16Ala polymorphism is associated with macroalbuminuria in Mexican type 2 diabetes patients: a comparative study and meta-analysis. BMC Med Genet. 2013;14:110.

40. Saify K. Genetic polymorphisms in the promoter region of catalase gene, creates new potential PAX-6 and STAT4 response elements. Mol Cell Biol Res Commun. 2016;5:97.

41. Saify K, Saadat I, Saadat M. Influence of A-21T and C-262T genetic polymorphisms at the promoter region of the catalase (CAT) on gene expression. Environ Health Prev Med. 2016;21:382-6.

42. Bresciani G, Cruz I, de Paz J, Cuevas M, González-Gallego J. The MnSOD Ala16Val SNP: relevance to human diseases and interaction with environmental factors. Free Radic Res. 2013:47:781-92.

43. Vasseur E, Quintana-Murci L. The impact of natural selection on health and disease: uses of the population genetics approach in humans. Evol Appl. 2013;6:596-607.

44. Stover P. Influence of human genetic variation on nutritional requirements. Am J Clin Nutr. 2006;83:436-42.

\section{Submit your next manuscript to BioMed Central and we will help you at every step:}

- We accept pre-submission inquiries

- Our selector tool helps you to find the most relevant journal

- We provide round the clock customer support

- Convenient online submission

- Thorough peer review

- Inclusion in PubMed and all major indexing services

- Maximum visibility for your research

Submit your manuscript at www.biomedcentral.com/submit

) Biomed Central 